\title{
Contribuições para a redução dos níveis de severidade dos acidentes nas vias de Brasília: riscos nas laterais das vias
}

\author{
Contributions to the reduction of accident severity levels on the \\ roads of Brasilia: risks on the sides of the roads
}

\section{Contribuciones a la reducción de los niveles de severidad de los accidentes en las carreteras de Brasilia: riesgos en las áreas adyacentes de las carreteras}

\author{
BUSON, Márcio Albuquerque ${ }^{1}$ \\ VALENTINI, Daniele Sales ${ }^{2}$ \\ 1Faculdade de Arquitetura e Urbanismo, Universidade de Brasília, Brasília, Brasil. mbuson@unb.br \\ ORCID: 0000-0002-4221-6673 \\ 2Departamento de Trânsito do Distrito Federal - DETRAN, Brasília, Brasil. danivalentini7@yahoo.com.br \\ ORCID: 0000-0002-5607-5795
}

Recebido em 26/02/2020 Aceito em 17/05/2020

\begin{abstract}
Resumo
Esse trabalho pressupõe que uma parcela dos acidentes de trânsito ocorridos em Brasília poderia ter sido evitada ou ter significativa diminuição dos níveis de severidade caso as vias de Brasília realmente tivessem sido projetadas, construídas e mantidas conforme as normas e padrões de segurança no trânsito. O objetivo do estudo foi o de identificar e mapear os pontos de risco alto nas áreas adjacentes das principais vias do Plano Piloto de Brasília. Foram identificados, classificados e mapeados um total de 2058 (dois mil e cinquenta e oito) pontos de risco alto. A partir desse levantamento foi possível apresentar ações para a redução da acidentalidade e dos níveis de severidade dos acidentes nas vias de Brasília.
\end{abstract}

Palavras-Chave: acidentalidade; severidade; obstáculos fixos; defesas laterais; ações sobre a via.

\begin{abstract}
This work presupposes that a large part of traffic accidents occurred in Brasilia could have been avoided or had a significant decrease in occurrence and severity if the Brasilia roads had actually been designed, constructed and maintained in accordance with traffic safety norms and standards. The objective was to identify and map the high-risk points in the adjacent areas of the main roads of the Brasilia. Were identified, classified and mapped a total of 2058 (two thousand and fifty-eight) high-risk points. From this survey it was possible to present actions for the reduction of accidentality and severity levels of accidents in the Brasilia roads.
\end{abstract}

Key-Words: accidentality; severity; fixed obstacles; lateral defenses; actions on the road.

\section{Resumen}

Este trabajo supone que una gran parte de los accidentes de tránsito ocurridos en Brasilia podrían haberse evitado o podrían haber tenido una disminución significativa en los niveles de severidad si las carreteras de Brasilia hubiesen sido realmente diseñadas, construidas y mantenidas de acuerdo con 
las normas y estándares de seguridad vial. El objetivo fue identificar y mapear los puntos de alto riesgo en las áreas adyacentes a las carreteras principales de Brasilia. Se identificaron, clasificaron y mapearon un total de 2058 (dos mil cincuenta y ocho) puntos de alto riesgo. A partir de este estudio, fue posible presentar acciones para la reducción de la accidentalidad y los niveles de gravedad de los accidentes en las carreteras de Brasilia.

Palabras clave: accidentalidad; severidad; obstáculos fijos; defensas laterales; acciones en la vía 


\section{Introdução}

A Organização Mundial da Saúde há algum tempo vem alertando o mundo sobre a magnitude e as consequências dos acidentes de trânsito. $O$ relatório mundial sobre prevenção de lesões causadas pelo trânsito (PEDEN et al., 2004) apresenta dados alarmantes sobre essa triste realidade mundial. Os acidentes de trânsito correspondiam naquela época a $22,8 \%$ de todas as mortes por acidente no mundo, o equivalente a 2,1\% das mortes, ocupando a nona posição entre as causas de morte em todo o mundo. No relatório de status global sobre segurança no trânsito, a OMS (2009) sinaliza que essa situação deve piorar até 2030 , com os acidentes de trânsito podendo ser a causa para $3,6 \%$ das mortes em todo o mundo.

O Centro de Gestão e Estudos Estratégicos (CGEE, 2012) afirma que morrem cerca de 1,3 milhão de pessoas por ano em razão dos acidentes de trânsito (quase 3.600 mortes diárias) e aproximadamente 50 milhões sofrem algum tipo de lesão - muitos ficando com sequelas físicas, mentais e/ou psicológicas que impedem uma vida normal. E ainda reforçam a ideia de que esse cenário vai se tornar ainda mais trágico se políticas adequadas não forem colocadas em prática, pois a previsão é que esses números irão crescer ainda mais, podendo atingir 1,9 milhão de óbitos no ano 2020 (estimativa considera um aumento de óbitos de $80 \%$ nos países em desenvolvimento).

No Brasil a violência no trânsito ainda faz quase 40 mil vítimas por ano, mesmo tendo havido uma redução de 16\% no número de mortes entre 2010 e 2015. Segundo a Associação Brasileira de Medicina de Tráfego (Abramet), os acidentes de trânsito já são a segunda causa de morte não natural evitável na população. Estima-se o valor de 19 bilhões de reais gastos com óbitos e feridos só em 2015 (AMBEV e FALCONI, 2017).

A pesquisa Ipea de custos dos acidentes de trânsito nos aglomerados urbanos de 2003 apresentou o resultado de 5,3 bilhões de reais por ano para todas as áreas urbanas brasileiras. Para atualizar esse valor utilizaram o método simples de atualização financeira pelo IPCA e os custos dos acidentes nas aglomerações urbanas brasileiras foram estimados numa faixa de 9,9 a 12,9 bilhões de reais no ano de 2014 (IPEA, 2015).

A tríade da acidentalidade é composta por três fatores causais ou fatores contribuintes: o humano, o viário-ambiental e o veicular. As suas contribuições na ocorrência dos acidentes são de difícil determinação com precisão, uma vez que podem contribuir separadamente ou de forma conjunta.

Sampedro (2006) afirma que embora o fator humano seja indicado como responsável pela maior parte dos acidentes de trânsito, as condições viárias propiciam a ocorrência desses incidentes, podendo induzir o homem a cometer erros. Considera também que atuações sobre a via produzem reduções mais efetivas do número e da severidade dos acidentes e apresentam uma melhor relação custobenefício quando comparadas com ações sobre os outros contribuintes da acidentalidade.

Nodari (2003) argumenta que o investimento em medidas de engenharia para simplificar o ambiente viário e facilitar a condução resulta mais simples e com menores investimentos que preparar motoristas para níveis de habilidade maiores. Neste sentido, ressalta que as medidas de engenharia são capazes de influenciar mudanças mais rápidas no comportamento do motorista do que medidas de educação ou fiscalização.

Dois focos claramente definidos são as bases das iniciativas para o Gerenciamento da Segurança Viária (GSV): as estratégias reativas (ou corretivas) e as estratégias proativas (ou preventivas). As proativas visam atenuar situações potenciais de risco presentes na via, evitando assim possíveis acidentes. Nodari (2003) considera que seja através de ações preventivas que avanços notáveis poderão ser alcançados na melhoria da segurança viária.

Tenório e Santos Júnior (2010) comentam que em Brasília, da sua concepção original rodoviarista às 
suas políticas de expansão e ocupação do solo, tudo tem reforçado a característica de que o carro é a medida tanto das suas políticas de planejamento urbano quanto das mais corriqueiras ações do poder público na cidade.

Brasília, planejada por Lucio Costa, é descrita por muitos como uma cidade pensada para os carros. Entretanto mesmo tendo sido planejada para os automóveis sempre teve problemas com acidentes de trânsito, muitos dos quais provocados pelas condições viárias. Esse trabalho pressupõe que uma boa parcela desses acidentes poderia ter sido evitada ou ter significativa diminuição da ocorrência e da severidade caso as vias de Brasília realmente tivessem sido projetadas, construídas e mantidas conforme os padrões de segurança.

Diversos são os fatores da infraestrutura viária e do meio ambiente que incidem sobre a segurança de motoristas, passageiros e pedestres: a geometria e traçado da via; a presença de obstáculos laterais; o estado técnico e superfície do pavimento; o estado técnico e credibilidade da sinalização; a presença e estado técnico dos acostamentos; as condições de drenagem; as condições de visibilidade e iluminação; a presença de pedestres e ciclistas na via; a presença de animais de grande porte; a chuva; as altas temperaturas; a neblina; e a neve.

Odgen (1996, apud NODARI, 2003) apresentou em 1996 estimava de que entre $25 \%$ e $30 \%$ do total de acidentes registrados em vias urbanas e rurais ocorrem devido a choques contra obstáculos colocados nas proximidades da pista. Nodari (2003) argumenta como se torna importante oferecer a maior segurança possível aos veículos desgovernados por meio do acondicionamento das áreas adjacentes e do gerenciamento dos obstáculos perigosos.

O objetivo desse trabalho é identificar e mapear nas vias de Brasília os pontos de risco nas áreas adjacentes das principais vias do Plano Piloto. A partir desse levantamento espera-se poder contribuir e apresentar ações para a redução da acidentalidade nas vias de Brasília, principalmente para a redução dos níveis de severidade dos acidentes. Trabalha-se com o conceito da "rodovia que perdoa" (ABNT NBR 15486:2016), utilizado para minimizar a severidade dos acidentes, permite um tratamento das laterais das vias de modo que veículos desgovernados que saiam da pista de rolamento encontrem uma lateral projetada para reduzir as consequências destes incidentes. Conforme essa mesma norma, independentemente do motivo que leve um veículo a sair da pista de rolamento, um ambiente lateral livre de obstáculos, com declividades suaves e estáveis, possibilita a redução da severidade do acidente.

\section{Procedimentos Metodológicos}

Esse trabalho pode ser descrito, quanto aos objetivos, como sendo uma pesquisa descritiva que visa a descrever as características das vias de Brasília quanto aos riscos relacionados com o acondicionamento inadequado das áreas adjacentes das vias.

Os procedimentos metodológicos envolvem o uso de observação sistemática através de inspeção de campo onde se observa, registra, analisa e ordena dados das vias urbanas de acesso rápido (caracterizadas por acessos especiais com trânsito livre, sem interseções em nível, sem acessibilidade direta aos lotes lindeiros e sem travessia de pedestres em nível) de Brasília. As vias arteriais, coletoras e locais não entraram nesse levantamento inicial, por terem limite de velocidade bem abaixo dos 60 $\mathrm{km} / \mathrm{h}$. Fazem parte do estudo as seguintes vias: Eixo Rodoviário Sul e Eixo Rodoviário Norte (Eixão Sul e Norte, DF-002), com limite máximo de velocidade de $80 \mathrm{~km} / \mathrm{h}$ e circulação de veículos diários média (VDM) acima de 6000. Os ERW Sul e Norte (Eixinhos W) e os ERL Sul e Norte (Eixinhos L), com limites máximo de velocidade de $60 \mathrm{~km} / \mathrm{h}$ e circulação de VDM acima de 6000 , não entraram no levantamento pelo valor de limite máximo de velocidade. Entretanto cabe ressaltar que nestas vias ocorrem as mesmas situações de pontos de alto risco de acidentes encontradas nos Eixão Sul e Eixão Norte. 
Procurou-se descobrir a frequência e o número de vezes com que os motoristas de Brasília se deparam com pontos de risco proporcionados pelo inadequado acondicionamento das áreas adjacentes das referidas vias urbanas. Após serem identificados, foram mapeados e as vias foram analisadas quanto aos seus potenciais níveis de risco.

Trata-se de um levantamento de dados através de documentos, legislação, visitas in loco, registros fotográficos e mapeamento dos pontos de risco. Para identificar os pontos de risco foram utilizadas as descrições e referências da ABNT NBR 15486:2016. Portanto, nesse estudo foram considerados pontos de risco a existência de perigos que possam elevar a severidade e as consequências de um acidente:

1) Locais que propiciem quedas em taludes críticos altos, ou seja, vias sobre aterros altos e/ou com taludes laterais íngremes (aclive ou declive) que não possuem defesas laterais. Segundo a ABNT NBR 15486:2016, as defesas laterais são consideradas necessárias na presença de aterros ou taludes com altura de $1,0 \mathrm{~m}$ e declividade $(\mathrm{V} / \mathrm{H}$, dimensão na vertical dividido pela dimensão na horizontal) de 0,7 ou superior ( $\mathrm{i} \geq 70 \%$ ); com altura de $2,0 \mathrm{~m}$ e declividade de 0,5 ou superior ( $i \geq 50 \%$ ); com altura de $3,0 \mathrm{~m} \mathrm{e}$ declividade de 0,4 ou superior ( $\mathrm{i} \geq 40 \%$ ); com altura de $4,0 \mathrm{~m}$ e declividade de 0,37 ou superior ( $i \geq$ $37 \%$ ); com altura de $5,0 \mathrm{~m}$ e declividade de 0,35 ou superior ( $\mathrm{i} \geq 35 \%$ ); com altura de $6,0 \mathrm{~m}$ ou superior e declividade de 0,33 ou superior ( $i \geq 33 \%$ ), conforme Figura 1.

Figura 1: Necessidade de proteção lateral em função de talude.

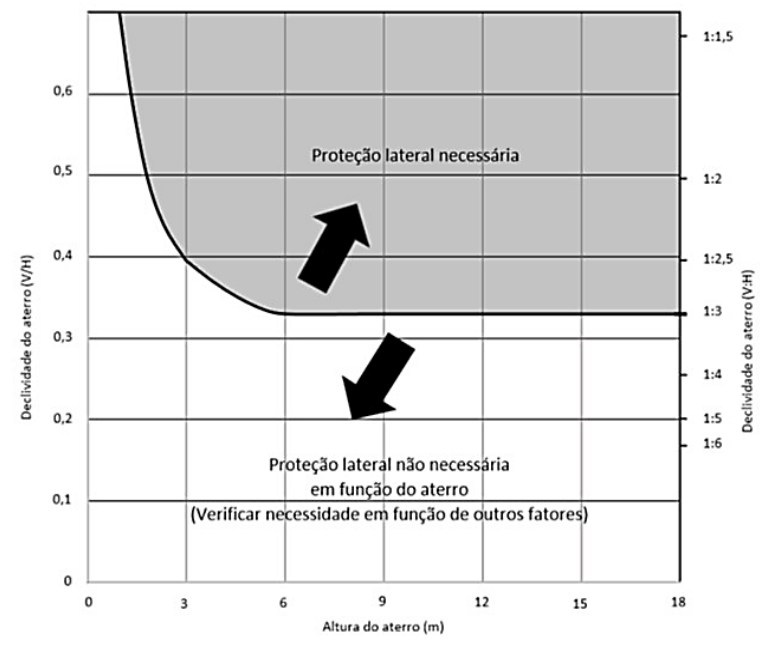

Fonte: ABNT NBR 15486 (2016)

2) Vias com obstáculos fixos sem proteção nas suas laterais e dentro da zona livre (área de recuperação), elementos naturais ou construídos, ou qualquer elemento rígido aflorando mais do que $10 \mathrm{~cm}$, situados na lateral da via que pela sua proximidade, em caso de acidente, produzem desacelerações acentuadas ou paradas abruptas, tais como: árvores com diâmetro maior que $10 \mathrm{~cm}$, bambuzal e rochas; postes de sinalização, iluminação e de transmissão de energia (não colapsíveis); elementos estruturais de pontes ou de suporte de propagandas e outros; elementos de drenagem e de infraestrutura; edificações.

As larguras das zonas livres de cada uma das vias estudadas foram calculadas conforme o item 4.1.1 da ABNT NBR 15486:2016. Para o Eixão Norte e Eixão Sul os valores das larguras das zonas livres são: de $6,0 \mathrm{~m}$ a $6,5 \mathrm{~m}$ para laterais com declives de $1 \mathrm{~V}: 6 \mathrm{H}(0,167)$ ou mais planos $(\mathrm{i} \leq 16,7 \%)$; de $7,5 \mathrm{~m}$ a $8,5 \mathrm{~m}$ para laterais com declives de $1 \mathrm{~V}: 5 \mathrm{H}$ a $1 \mathrm{~V}: 4 \mathrm{H}$, ou seja, entre 0,2 e $0,25(20 \% \geq i \leq 25 \%)$; para laterais com declives de $1 \mathrm{~V}: 3 \mathrm{H}(0,33)$ ou mais inclinados ( $\mathrm{i} \geq 33 \%)$ até o pé do aterro deve estar livre de obstáculos fixos; de $4,5 \mathrm{~m}$ a $5,0 \mathrm{~m}$ para laterais com aclives de $1 \mathrm{~V}: 3 \mathrm{H}(0,33)$ ou mais inclinados $(\mathrm{i} \geq$ $33 \%)$; de 5,5m a 6,0m para laterais com aclives de $1 \mathrm{~V}: 5 \mathrm{H}$ a $1 \mathrm{~V}: 4 \mathrm{H}$, ou seja, entre 0,2 e $0,25(20 \% \geq i \leq$ 
$25 \%$ ); e de $6,0 \mathrm{~m}$ a $6,5 \mathrm{~m}$ para laterais com aclives de $1 \mathrm{~V}: 6 \mathrm{H}(0,167)$ ou mais planos ( $\leq 16,7 \%)$, conforme Tabela 1.

Tabela 1: Cálculo da zona livre, em metros.

\begin{tabular}{|c|c|c|c|c|c|c|c|}
\hline \multirow{3}{*}{$\begin{array}{l}\text { Velocidade de } \\
\text { projeto } \mathrm{km} / \mathrm{h}\end{array}$} & \multirow{3}{*}{ VDM } & \multicolumn{6}{|c|}{ Declividade Lateral } \\
\hline & & \multicolumn{3}{|c|}{ Pista de rolamento- } & \multicolumn{3}{|c|}{ Pista de rolamentop } \\
\hline & & $\begin{array}{l}\text { 1V:6H ou } \\
\text { mais plano }\end{array}$ & $\begin{array}{l}\text { 1V:5H a } \\
1 \mathrm{~V}: 4 \mathrm{H}\end{array}$ & 1V: $: 3 \mathrm{H}$ & $1 \mathrm{~V}: 3 \mathrm{H}$ & $\begin{array}{l}1 \mathrm{~V}: 5 \mathrm{H} \mathrm{a} \\
1 \mathrm{~V}: 4 \mathrm{H}\end{array}$ & $\begin{array}{l}1 \mathrm{~V}: 6 \mathrm{H} \text { ou } \\
\text { mais plano }\end{array}$ \\
\hline \multicolumn{8}{|c|}{ Eixo Rodoviário Sul e Norte (Eixāo, DF-002) } \\
\hline 80 & $>6000$ & $6,0-6,5$ & $7,5-8,5$ & * & $4,5-5,0$ & $5,5-6,0$ & $6,0-6,5$ \\
\hline \multicolumn{8}{|c|}{ ERW Sul e Norte (Eixinhos W) e os ERL Sul e Norte (Eixinhos L) } \\
\hline 60 & $>6000$ & $4,5-5,0$ & $5,0-5,5$ & * & $4,5-5,0$ & $4,5-5,0$ & $4,5-5,0$ \\
\hline
\end{tabular}

Fonte: ABNT NBR 15486 (2016), adaptada pelos autores.

\section{Pontos de risco alto}

Um dos ícones do projeto do Plano Piloto de Brasília são as "tesourinhas", passagens de nível para que evitem os cruzamentos de veículos nas principais vias, nomeadamente, no Eixão Sul e Norte e Eixinhos Sul e Norte. Para execução das vias de contorno das tesourinhas foram produzidos taludes com declividades extremamente elevadas, algumas com inclinações acima dos 200\% (V2:H1), e cujas laterais das vias só recebem proteção nas áreas logo acima dos vãos dos viadutos.

Figura 2: Vista aérea de um conjunto de tesourinhas da Asa Sul em Brasília. Detalhe para as defesas instaladas apenas acima dos vãos dos viadutos.

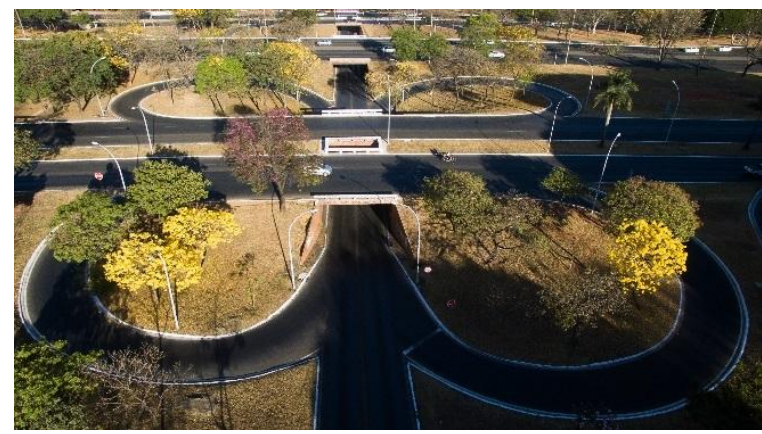

Fonte: Lula Lopes / Secretaria de Turismo do DF.

Essas poucas proteções existentes nas tesourinhas são defesas com vigas apoiadas em pilaretes de concreto armado, as quais acabam também sendo pontos de risco alto, por se transformarem em obstáculos fixos posicionados nas laterais das pistas de rolamento por não estarem de acordo com as normas de segurança.

Figura 3: Colisão direta com proteção de concreto armado no Eixinho Norte.

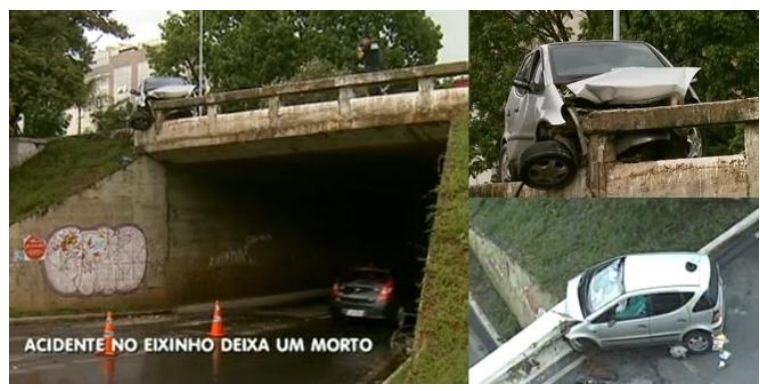

Fonte: DF Record / noticias.r7.com 
Todo o Eixo Rodoviário Sul e Norte (Eixão e Eixinhos) recebeu um tratamento paisagístico ao longo de todas as laterais das vias estudadas, onde foram plantadas árvores dentro das zonas livres, inclusive nos taludes altos próximos das tesourinhas (ver Figura 2). Boa parte desses elementos paisagísticos se constituem em obstáculos fixos (Figura 4).

Figura 4: Veículo cai de talude alto e colide com árvores dentro da zona livre das laterais de uma tesourinha do Eixinho Norte.

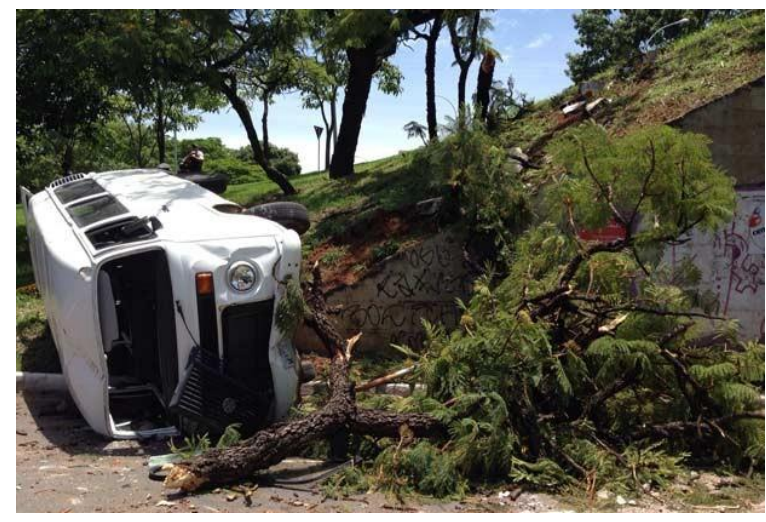

Fonte: Gabriel Luiz / g1.globo.com

Outra proposta do projeto de Lúcio Costa foram as passagens de pedestres e ciclistas por debaixo do Eixão e Eixinhos. Entretanto essas passagens foram executadas sem qualquer proteção aos veículos que circulam pelas vias. Taludes altos e vãos livres sem defesas laterais oferecem risco alto e podem aumentar a severidade dos acidentes nessas áreas.

Na Figura 5 é possível perceber a total falta de proteção na área próxima da passagem subterrânea de pedestres, bem como a presença de árvores de grande porte dentro da zona livre da lateral da via.

Figura 5: Carro desgovernado sai do Eixão e cai no vão de passagem de pedestres.

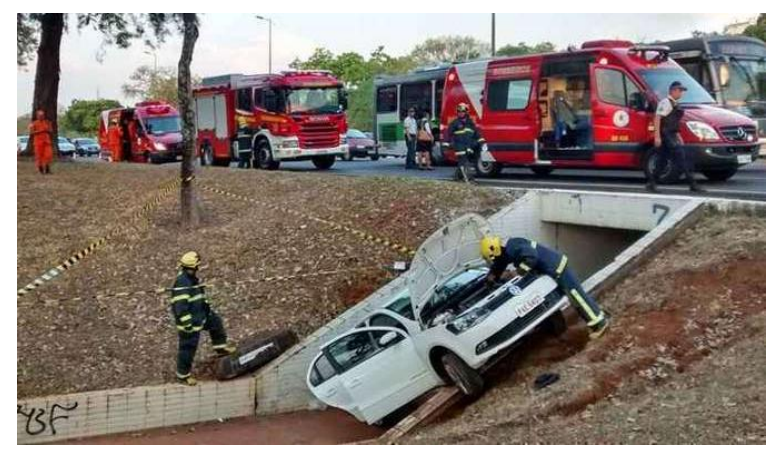

Fonte: Corpo de Bombeiros Militar do DF / Divulgação.

A estrutura dos viadutos dos Eixinhos $L$ e $W$ na Asa Sul não tem continuidade no canteiro central, o que resulta num vão aberto, o qual foi protegido por defesas de concreto armado (ver Figuras 2 e 6). Entretanto essas defesas também se transformaram em obstáculos fixos que aumentam a severidade dos acidentes. 
Figura 6: Carro colide de frente em mureta de proteção no Eixinho Sul.

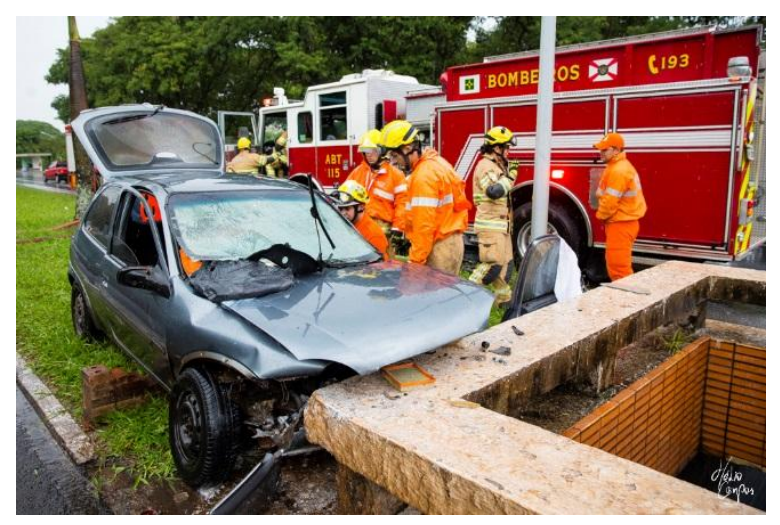

Fonte: Hélio Campos / 193bombeiros.blogspot.com.br.

As defesas laterais de concreto armado dispostas acima dos viadutos das tesourinhas em muitos acidentes acabam por não evitar a saída dos veículos das vias, são arrancadas e arremessadas nas vias que passam por debaixo do Eixão e Eixinho.

Figura 7: Carro arranca mureta de proteção e cai de $5 \mathrm{~m}$ de altura sobre via abaixo do Eixão Sul.

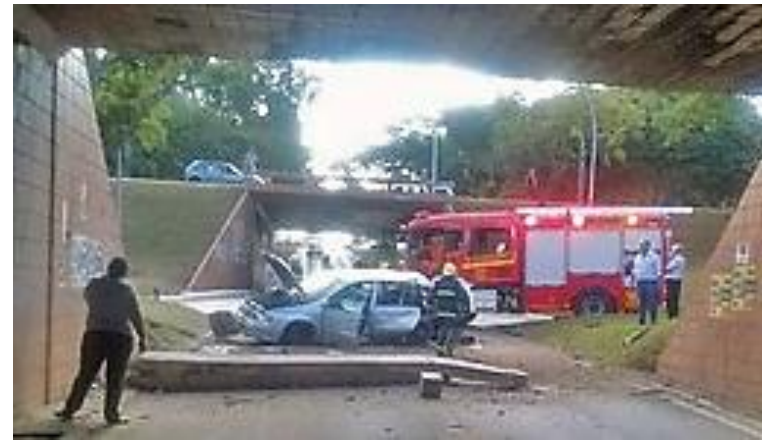

Fonte: TV Globo / Divulgação

\section{Mapeamento dos pontos de risco}

Foram identificados, mapeados e classificados um total de 2058 (dois mil e cinquenta e oito) pontos de risco alto nas vias analisadas. Os pontos de risco foram mapeados em cada via e classificados como: a) presença de talude crítico alto sem defesas laterais; b) presença de obstáculo fixo sem proteção e dentro da zona livre; c) presença de talude crítico alto sem defesas laterais e com obstáculo fixo dentro da zona livre. Os taludes foram classificados pelas faixas de declividade constantes na ABNT NBR 15486:2016 e os obstáculos fixos de acordo com o tipo, conforme Tabela 2.

Tabela 2: Mapeamento dos pontos de risco.

\begin{tabular}{lllllll} 
& Muretas & Postes & Árvores & $\begin{array}{l}\text { Caixas de } \\
\text { concreto }\end{array}$ & Taludes & TOTAIS \\
\hline Eixão Sul & 28 & 291 & 633 & 44 & 58 & 1054 \\
Eixão Norte & 30 & 305 & 566 & 56 & 47 & 1004 \\
TOTAIS & 58 & 596 & 1199 & 100 & 105 & 2058 \\
\hline
\end{tabular}

\section{Conclusões}


O mapeamento dos pontos de risco demonstra claramente que tanto o Eixo Rodoviário Sul e Norte (Eixão, DF-002) quanto os ERW Sul e Norte (Eixinhos W) e os ERL Sul e Norte (Eixinhos L) do Plano Piloto de Brasília não foram projetados, construídos ou mantidos conforme as normas de segurança vigentes. Praticamente na totalidade de suas extensões ocorrem pontos de risco alto que com toda a certeza não seguem as normas de segurança e contribuem para elevar a severidade e as consequências na ocorrência de acidentes de trânsito.

O projeto paisagístico das laterais do Eixão e Eixinhos produz beleza e encantamento, mas também oferece muitos pontos de risco alto, pois boa parte de seus elementos estão dispostos dentro das zonas livres das vias, se constituindo em obstáculos fixos.

Os taludes nas laterais das vias com inclinações muito acima das permitidas quando sem proteções constituem risco alto e potenciais agravadores dos níveis de severidade dos acidentes.

Conclui-se que faltam elementos de proteção nas laterais das vias para se garantir uma adequada segurança aos usuários do sistema rodoviário composto pelos Eixão Sul e Norte (DF-002) do Plano Piloto de Brasília e para que essas rodovias passem a estar em conformidade com as recomendações das normas de segurança vigentes.

\section{Considerações finais}

O Conjunto Urbanístico de Brasília é tombado. Segundo o IPHAN, o que está sob proteção federal (tombamento histórico) é a concepção urbana da cidade, materializada na definição e interação de suas quatro escalas urbanísticas - monumental, gregária, residencial e bucólica. Portanto, o que se busca preservar são as características e a articulação dessas quatro escalas.

Desde que as passagens de nível (tesourinhas) foram executadas, antes mesmo da inauguração de Brasília, já não ofereciam proteção adequada. Essa situação de risco perdura por décadas e já foi responsável pelo aumento da severidade e das consequências em diversos acidentes. Muitas vidas foram perdidas e muitas sequelas estão associadas a essa situação de falta de proteção e falta de segurança. Mudanças na estrutura e materiais constituintes das muretas de proteção dos viadutos das tesourinhas e demais proteções com mesmas características espalhadas pela cidade, bem como a inclusão de defesas laterais nos taludes altos das tesourinhas são uma necessidade real e urgente. Algo que consideramos não afetar o tombamento da cidade e que corrige a lacuna de um projeto e construção que efetivamente não garantem a segurança no trânsito.

Exemplos de intervenções em patrimônio edificado de Brasília, por questões de segurança e atendimento de normas, já ocorreram, como no caso da inclusão de escadas de emergência nas fachadas dos edifícios da Esplanada dos Ministérios. Consideramos que as adequações às normas sugeridas para as vias estudadas não se comparam às modificações realizadas, por exemplo, nos Ministérios e nem interferirão na concepção urbana da cidade ou na interação de suas quatro escalas urbanísticas.

\section{Estudos futuros}

Para se ter real caracterização da situação das rodovias do Plano Piloto de Brasília e se alcançar maiores níveis de segurança, a redução da acidentalidade e minimizar a severidade e as consequências na ocorrência de acidentes no trânsito se faz necessário mapeamento das demais vias, bem como com os demais aspectos relacionados à segurança no trânsito, tais como: geometria e traçado; estado técnico e superfície do pavimento; estado técnico e credibilidade da sinalização; presença e estado técnico dos acostamentos; condições de drenagem; e condições de visibilidade e iluminação; emprego de elementos complementares de segurança (delimitadores, canalizadores, marcas refletivas no pavimento, defesas laterais). 


\section{Referências}

ABNT (2016) NBR 15486 - Segurança no tráfego - Dispositivos de contenção viária - Diretrizes de projeto e ensaios de impacto. Associação Brasileira de Normas Técnicas, Rio de Janeiro.

AMBEV e FALCONI (2017) Retrato da Segurança Viária 2017. Disponível em https://www.ambev.com.br/conteudo/uploads/2017/09/Retrato-da-Seguran\%C3\%A7a-

Vi\%C3\%A1ria_Ambev_2017.pdf

CGEE (2012) Subsídios em CT\&I para uma Política de Segurança no Trânsito - Relatório Final. Centro de Gestão e Estudos Estratégicos, Brasília.

IPEA (2015) Estimativa dos Custos dos Acidentes de Trânsito no Brasil com Base na Atualização Simplificada das Pesquisas Anteriores do Ipea - Relatório de Pesquisa. Instituto de Pesquisa Econômica Aplicada, Brasília.

Nodari, C. (2003) Método de avaliação da segurança potencial de segmentos rodoviários rurais de pista simples. Tese de Doutorado em Engenharia de Produção. Universidade Federal de Rio Grande do Sul. Disponível em http://www.producao.ufrgs.br/arquivos/publicacoes/christine_t_nodari.pdf

OMS (2009) Global status report on road safety: time for action. Genebra, World Health Organization. Disponível em www.who.int/violence_injury_prevention/road_safety_status/2009. Acesso em Jan/2019.

Peden, M.; Scurfield, R.; Sleet, D.; Mohan, D.; Hyder, A. A.; Jarawan, E.; e Mathers, C. (2004) World report on road traffic injury prevention. World Health Organization, Genebra.

Sampedro, A. T. (2006) Procedimento para Avaliação da Segurança de Tráfego em Vias Urbanas. Dissertação de Mestrado, Instituto Militar de Engenharia, Rio de Janeiro.

Tenório, G.; e Santos Júnior, R. (2010) O Programa de Transporte Urbano de Brasília: discussão e especulações - uma abordagem ambiental. Paranoá: Cadernos De Arquitetura E Urbanismo, 5(5). https://doi.org/10.18830/issn.1679-0944.n5.2010.15483 